\title{
SETTLEMENT-INDUCED BUILDING DAMAGE ASSESSMENT USING MT-INSAR DATA FOR THE CROSSRAIL CASE STUDY IN LONDON
}

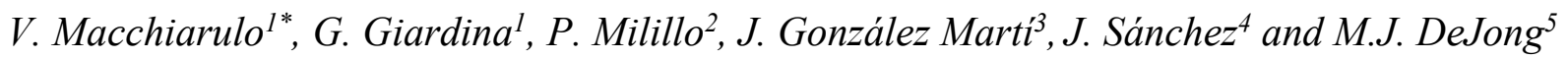 \\ ${ }^{I}$ Department of Architecture and Civil Engineering, University of Bath, Bath, United Kingdom \\ ${ }^{2}$ NASA Jet Propulsion Laboratory, California Institute of Technology, Pasadena, USA \\ ${ }^{3}$ Sixense Group, London, United Kingdom \\ ${ }^{4}$ TRE-Altamira, Barcelona, Spain \\ ${ }^{5}$ Department of Civil and Environmental Engineering, University of California, Berkeley, USA \\ *v.macchiarulo@bath.ac.uk
}

\begin{abstract}
The expansion of modern cities causes a growing demand for efficient transport facilities, motivating the realization of large urban tunnelling projects. A major concern during tunnelling operations is the evaluation of the response of existing buildings to induced ground movements, with a considerable economic impact on the total project cost. Since traditional monitoring is based on costly in-situ installations, only a limited amount of observations is typically provided for each structure. Without a systematic increase in the availability of monitored building deformations, lesson learned from previous projects cannot be effectively used to improve existing damage assessment procedures. Satellite Interferometric Synthetic Aperture Radar (InSAR) techniques, providing high quality measurements of building deformations, have been recently validated to be used in combination with damage assessment procedures. In particular, Multi-Temporal InSAR can provide cumulative displacement maps for a high density of monitoring points with millimetric accuracy, enabling to assess buildings nearby the excavation. In this paper, results from post-tunnelling damage assessment of hundreds of buildings along the Crossrail route in London are presented. By exploiting InSAR-based displacements, a semi-automated assessment tool is used to investigate the structural response to tunnelling-induced settlements. Results are compared to the ones obtained through the greenfield-based assessment, enabling to evaluate their accuracy. The application of the proposed method to real case studies highlights its potential for the quasi-real time identification of building damage levels over extensive area. This semi-automatic procedure can positively impact the construction industry, enabling to improve traditional damage assessment strategies and to complement ground-based monitoring systems.
\end{abstract}

\section{Notation}

$D:$ tunnel diameter

$\Delta^{\text {hog. }}$ relative deflection in hogging

$\Delta^{\text {sag. }}$ relative deflection in sagging

$\varepsilon$. actual critical strain

$\varepsilon_{b}$ : bending strain

$\varepsilon d$ diagonal strain

$\varepsilon_{g r}$ : greenfield critical strain

$H$ : building height

$i$ : trough width

$L$ : building length

$L^{\text {hog: }}$ building length in hogging
$L^{\text {sag. }}$ building length in sagging

$z$ : tunnel depth

\section{Introduction}

The risk of subsidence after the realization of large subway systems represents a relevant economical issue for the construction industry. A systematic damage assessment is essential to protect all the structures and services near the excavation, with a special attention to heritage buildings. In order to perform a rational assessment of the properties potentially affected by tunnelling operations, buildings are traditionally monitored by means of expensive in-situ installations. Examples of monitoring systems are Precise Levelling Prisms (PLP), British Research Established (BRE) sockets and Robotic Total Stations (RTS) (Burland et al., 2001; González Martí et al., 2015; Korff and Kaalberg, 2014). Due to the high cost for the installation and the maintenance of these instruments, only a limited number of points on buildings are typically monitored (DeJong et al., 2019). As a consequence, the first level of the assessment is conventionally based on a greenfield assumption for the settlement profile (Burland, 
2012; Crossrail, 2011) and the final damage prediction tends to overestimate the actual damage level.

Over the last two decades, radar scientists have been developing advanced algorithms to process Interferometric Synthetic Aperture Radar (InSAR) data, enabling measurement of the temporal evolution of different events, like earthquakes, Volcanoes eruptions (Salzer et al., 2017), landslides and human-induced processes (Di Martire et al., 2014; Milillo et al., 2016; Yun et al., 2015). Among this new generation of InSAR techniques, the Multi Temporal InSAR (MT-InSAR) approach is capable of providing information about the deformations in time for a high density of points located on structures and ground surfaces (Ferretti et al., 2001), with a level of resolution suitable for damage assessment applications. Several studies (Arangio et al., 2014; Cerchiello et al., 2017; Peduto et al., 2017; Tapete and Cigna, 2012) have demonstrated the capability of these techniques to detect the spatial and temporal distribution of displacements in urban areas. Milillo et al. (2018), Perissin et al. (2011) and Pratesi et al. (2015) have recently shown that multi temporal measurements provide a dense set of displacements not accessible with traditional precise levellings. Giardina et al. (2019) compared ground scatterers displacements with the measurements acquired by PLP to verify the quality of MTInSAR data, validating an assessment approach based on the MT-InSAR measurements.

This paper presents a semi-automatic procedure utilizing InSAR-measured displacements for assessing the potential damage of buildings affected by the tunnel excavation. COSMO-SkyMed SAR data have been used to evaluate the settlement-induced deformations of 416 buildings along the Crossrail twin tunnels in London. The assessment highlights the benefits of this approach for investigating the building influence on the structural deformations induced by tunnelling.

\section{Methodology}

\subsection{Multi-Temporal InSAR}

The Multi-Temporal InSAR (MT-InSAR) is a remote sensing technique, developed in the late 1990s to improve the traditional SAR Interferometry. By using long stacks of SAR images, this technique allows to measure the temporal and spatial evolution of deformations affecting ground surfaces and structures (Crosetto et al., 2005; Ferretti et al. 2000). The processing technique used for retrieving relative displacements from the large set of SAR acquisitions is called Persistent (or Permanent) Scatterer Interferometry (PSI) and it is based on the identification of pixels showing amplitude stability over a sequence of interferograms (Ferretti et al., 2001). By searching elements on the ground (referred to as Permanent Scatterers, PS) which provide stable radar reflections back to the satellite, the PSI techniques allow mapping of superficial deformations over wide areas with a high spatial resolution. The possibility of this technique to achieve a millimeter sensitivity on a single displacement measurement has been proved by Ferretti et al., 2007 and Fornaro et al., 2013. In addition, the physical nature of persistent scatterers makes the PS techniques especially effective in urban areas.

In this work, the monitoring of building displacements due to the Crossrail tunnelling project in London was performed exploiting a set of spaceborne SAR data acquired through the COSMO-SkyMed system (Milillo et al., 2018). A total of 72 SAR images from April 2011 to December 2015 were processed with a MT-InSAR technique using the SARPROZ software package (Perissin et al., 2011). The available dataset focuses on a $25 \mathrm{~km}^{2}$ area in the central London, between the stations of Paddington and Farringdon, and was used to generate the cumulative displacements map shown in Figure 1. Negative values, indicating subsidence, correspond to the PS moving away from the space-borne sensor, while positive values refer to displacements towards the satellite. In the presented case, orange and red scatterers highlight the ground settlement above the twin tunnels.

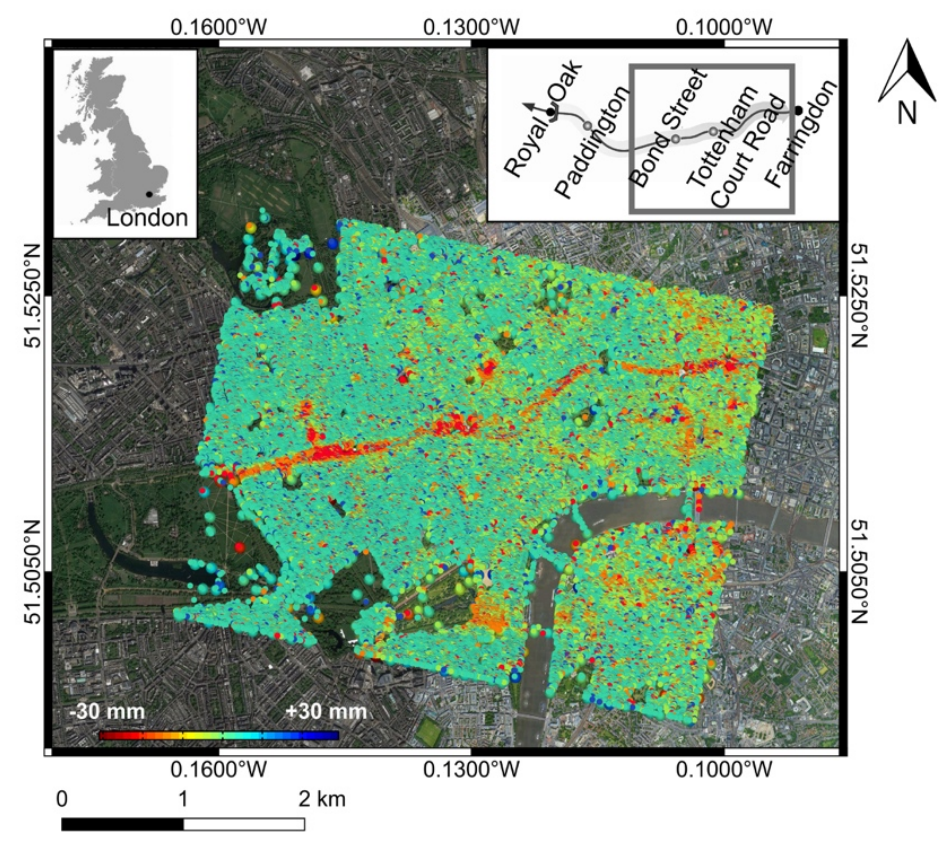

Figure 1: Cumulative displacement map over the Crossrail alignment in central London. The monitored area, between Paddington and Farringdon stations, corresponds to a sub-area of the Drive $\mathrm{X}$ section.

\subsection{Semi-automated assessment procedure}

This section presents a semi-automated procedure exploiting the MT-InSAR approach for analyzing the settlement-induced damage to buildings adjacent to excavations. The procedure is based on a multidisciplinary approach involving the use of satellite radar interferometric data, geotechnical information and databases of building features.

The Crossrail alignment is characterized by two tunnels of 7.18 $\mathrm{m}$ diameter and a variable depth reaching a maximum of $40 \mathrm{~m}$. Values of the tunnel depth $z$ and soil parameters have been linearly interpolated in order to establish a precise correspondence between the monitored structures and the local 
geometry of the tunnels. A volume loss of $0.7 \%$ has been adopted across all the analysis, according to the observations presented in DeJong et al. (2018). Figure 2 shows the tunnel geometry and deformation parameters for a typical settlement trough.

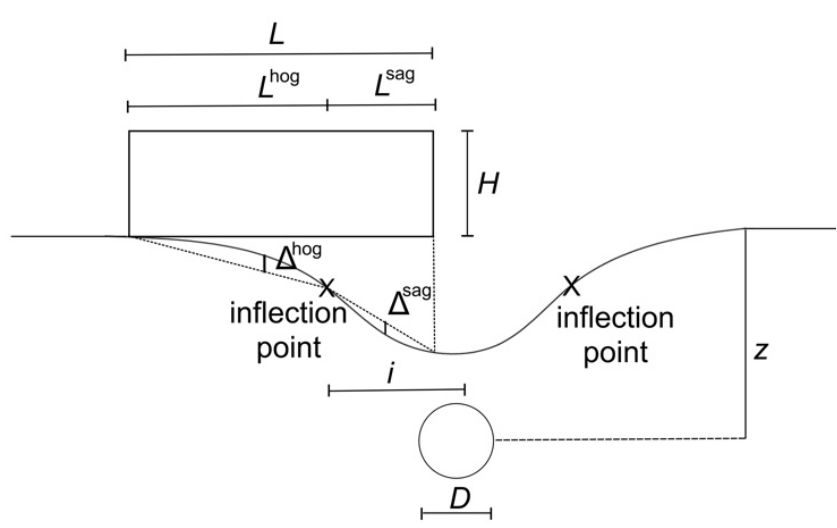

Figure 2: Typical profile of a tunneling-induced settlement trough.

The building data used in the analysis have been obtained from the inventory maps provided by Crossrail. The database shows the construction material, the foundation type and the age of construction of most of the edifices along the Crossrail route. Based on this information, different classes of residential structures have been identified and recorded in the form of different layers in a Geographic Information System. Then, an overlay-based procedure has been implemented to merge the different building features and identify structural aggregates.

The developed tool receives as an input any information related to the tunnel geometry, building properties and the set of InSAR measured displacements. The algorithm is able to relate the diverse information and to implement the damage assessment for the structural aggregates within the monitored area. According to the semi-empirical model proposed by Burland and Wroth (1974), each block of connected buildings is schematized as a linear elastic beam of length $L$, height $H$ and unit thickness. A unique value for the material parameter $(E / G=2.6)$ has been adopted for all the structures, but more detailed procedures could be implemented in the future.

The procedure consists in two main steps. The first part of the algorithm is based on a greenfield assumption (i.e. the tunnelling-induced settlement profile is evaluated disregarding the influence of surface structures). The Gaussian settlement trough proposed by Peck (1969) is applied to the building equivalent linear elastic beam to calculate the deflection ratios $\Delta / L$ in hogging and sagging (Figure 2). Since most of the monitored buildings are affected by two tunnels, each tunnel is assumed to generate a Gaussian shaped settlement, and their effect is then combined (Crossrail, 2011). The possible configurations given by the combination of the two tunnels are shown in Figure 3. Then, according to Burland and Wroth (1974), Timoshenko's equations (Timoshenko, 1957) are used to calculate the bending strain, $\varepsilon$, and the shear strain, $\varepsilon d$, of the beam, distinguishing between the sagging and hogging deformation. In the end, critical strains, $\varepsilon$, are determined for each structure. The critical strains provide an indication of the damage potentially affecting the building.

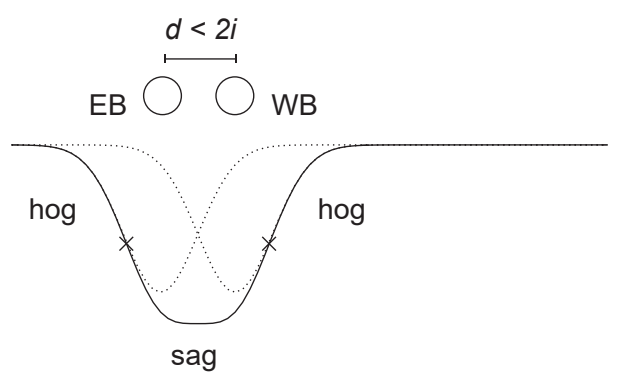

$\times$ inflection point
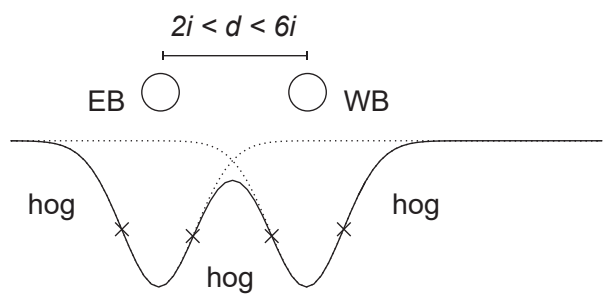

sag sag

$\times$ inflection point

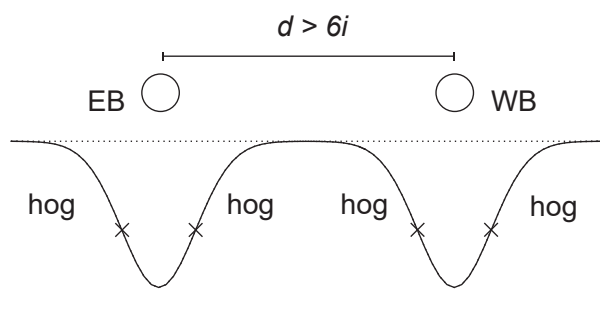

sag

sag

$\times$ inflection point

Figure 3: Settlement trough combinations for two tunnels (Crossrail, 2011; after Giardina et al., 2019).

The second part of the algorithm exploits the building displacements measured by means of the MT-InSAR technique. Permanent scatterer points are interpolated and used to generate the settlement trough for each building, based on a modified Gaussian function (see Giardina et al., 2019, for further details). Then, the building settlement trough is used to calculate deflection ratios and critical strains, adopting the approach proposed by Burland and Wroth (1974). This curve, derived from the MT-InSAR building displacements, contains information about the soil-structure interaction and allows a more direct approximation of the maximum strains of the building using the collected data and an equivalent beam model. Finally, the tool interfaces with a Geographical Information System and results are visualized in the form of damage maps. 


\section{Results}

The monitored area includes 1036 edifices, consisting of load bearing masonry buildings and concrete framed structures, built in different ages and relying on different foundation types. Figure 4 shows the distribution of these features for the buildings along the route.
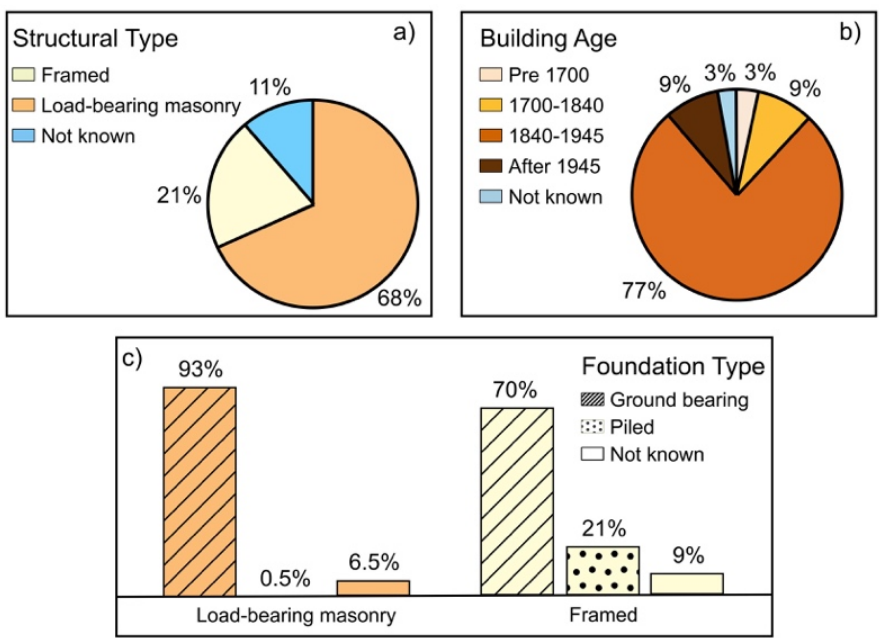

Figure 4: a) Structural typologies for the buildings in the monitored area; b) Age of construction-based classification; c) Foundation types intersected with the structural typology.

Figure 4(a) highlights that most of the buildings in the monitored area are load bearing masonry structures $(68 \%)$, while $21 \%$ are framed structures. If this information is intersected with the foundation type (Figure 4(c)), it is evident that the majority of buildings are resting on shallow foundations (about 93\% for load-bearing masonry and 70\% for framed structures), and $21 \%$ of framed structures are built on piles. Building construction periods have been categorized according to the criteria adopted by the DDCMS (2010) for the identification of historical value buildings, distinguishing between the five categories shown in Figure 4(b). The classification indicates that most of the buildings in the area (about 77\%) were built between the second half of the 19th century and the war period. These consist of independent buildings and houses organized in terraces. Georgian houses and more ancient buildings represent $9 \%$ and $3 \%$ of the total buildings, respectively. Post-war buildings represent $9 \%$ of the case studies and they mainly consist of big concrete framed structures, relying on piles or deep foundations.

By exploiting an overlay-based procedure, the different building features have been intersected and used to identify edifices behaving as a unique structural block. After this process, 776 building aggregates (i.e. independent structures) have been recognized and their geometries were used as input in the algorithm. The assessment has been successful carried out over 416 buildings, for which the available number of PS allowed a reliable fitting to be performed (Giardina et al., 2019).
The calculation of the actual maximum strains has shown that the settlement did not have significant consequences on the buildings in the monitored area. In order to establish a correlation between the maximum deformations and the potential damage, three levels of severity, identified by letters A, B and C, have been defined. These categories, adapted from the classification proposed by Boscardin and Cording (1989) and Burland et al. (1977), all relate to a negligible risk of damage and correspond to three different ranges of the maximum strain $\varepsilon$, with increasing values from $A$ to $C$. Note that the effect of horizontal strains have been neglected in this study. Figures 5 and 6 show the distribution of the level of damage for the buildings in the monitored area. Figure 5 shows damage predictions based on the MT-InSAR-derived displacements, while Figure 6 shows damage predictions based on the greenfield assumption, respectively.

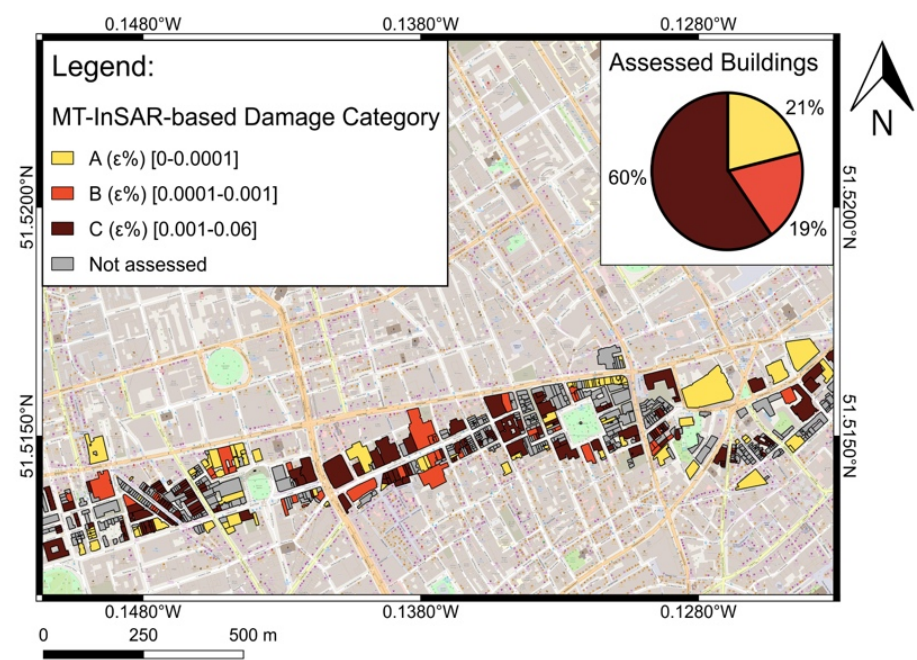

Figure 5: Damage map based on the InSAR-measured displacements for the buildings in Drive X.

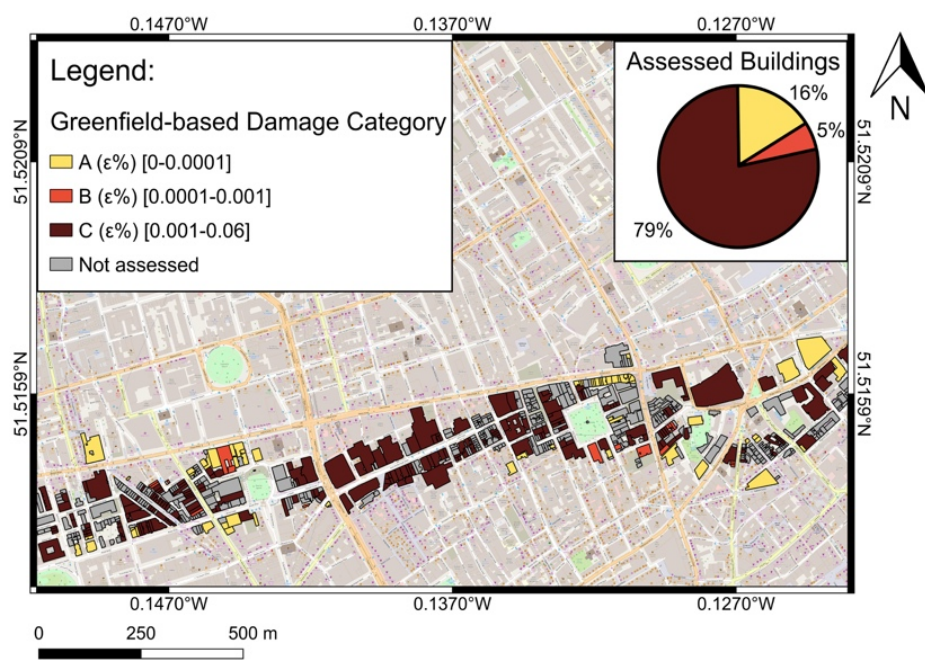

Figure 6: Damage map based on the greenfield displacements for the buildings in Drive $\mathrm{X}$. 
Results based on MT-InSAR measurements show that $60 \%$ of buildings fall into damage category C, $19 \%$ in B and $21 \%$ in A (Figure 5). Results based on the Gaussian settlement profile indicate that the $79 \%$ of the assessed buildings are assigned to the highest category of damage $\mathrm{C}$, while $5 \%$ and $16 \%$ of the structures fall into categories B and A, respectively (Figure 6). The comparison between the two maps confirm that the greenfield-based prediction is more conservative.

The availability of MT-InSAR-based results for such a large database of structures enable to analyse the correlation between building deformation and building geometries. In order to compare the results obtained from the MT-InSAR-based and greenfield-based displacements, the ratio between MT-InSARbased and greenfield-based critical strains has been related to the building aspect ratio $H / L$, obtaining the distribution presented in Figure 7.

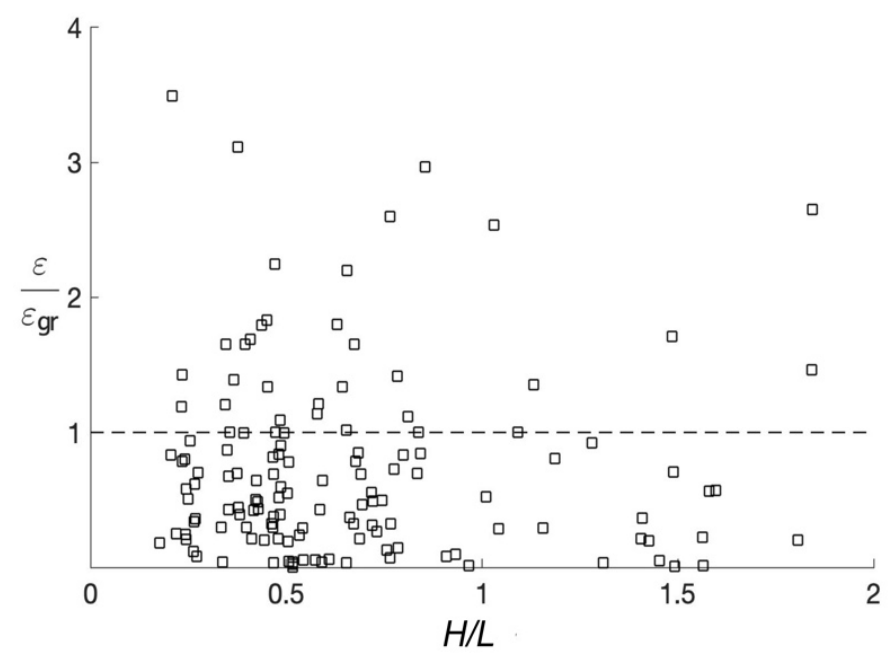

Figure 7: MT-InSAR/greenfield critical strain ratio vs the height-to-length ratio.

The results show that for most of the building aggregates the greenfield assessment overestimates the induced deformation. This means that the presence of the structure usually reduces the curvature of the settlement profile, confirming that the approach neglecting the soil-structure interaction is generally conservative. Most of the cases in which the MT-InSAR-based strains are larger than the greenfield strains correspond to structural blocks with an aspect ratio smaller than one. In addition, it has been observed that the majority of the cases exceeding the dotted line correspond to buildings located in the pure hogging region or located above the tunnel centreline.

The ratio between actual and greenfield strains has been also investigated separately for bending and shear, as defined by Burland and Wroth (1974), in relation with the height-to-length ratio (Figures 8 and 9). Then, MT-InSAR-based strains have been used to evaluate the bending over shear strain ratio (Figures 10 and 11). In both cases the sagging and the hogging regions are analysed separately. Thus, while in Figure $7 \mathrm{H} / \mathrm{L}$ considered the total length $L$ of the structure, in Figures 8 to 11 the aspect ratio refers to the part of the building located in the hogging or sagging region.
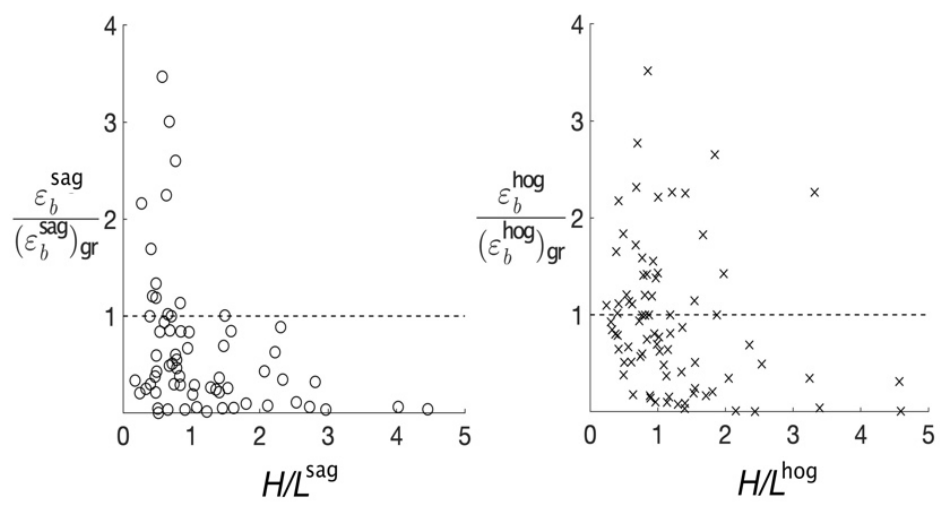

Figure 8: Bending strain ratio in sagging (a) and hogging (b) vs the aspect ratio.
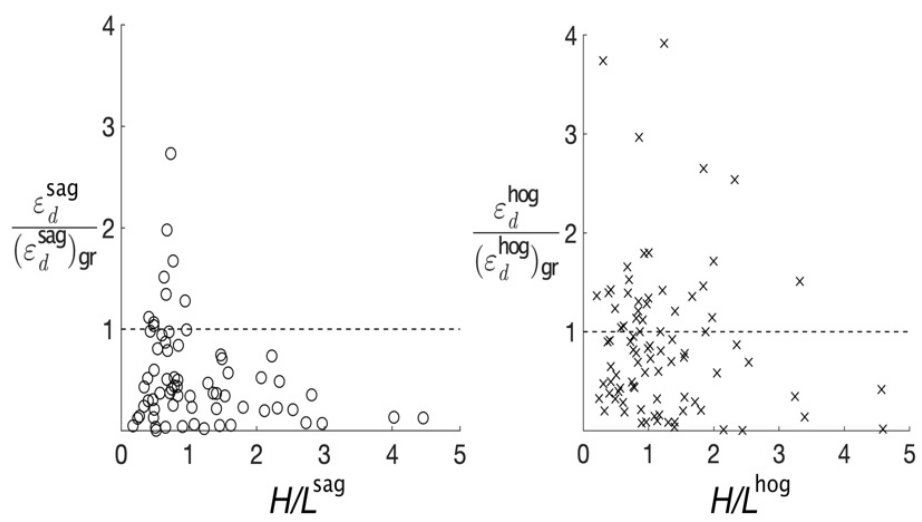

Figure 9: Diagonal strain ratio in sagging (a) and hogging (b) vs the aspect ratio.

Figure 8(a) shows that MT-InSAR-based bending strains calculated for the part of the building located in the sagging zone are usually smaller than the greenfield strains, except for a few cases with $H / L<1$. In the hogging zone (Figure 8(b)) a larger number of cases exhibit MT-InSAR-based bending strains larger than greenfield strains. A similar observation can be made for the shear strains (Figure 9).

Figures 10 and 11 show the bending-shear strain ratio for the hogging and sagging deformation, respectively. Both the plots show that there is an inverse relation between the bendingshear ratio and the aspect ratio. In detail, in the sagging configuration the bending deformation mode is prevalent for aspect ratios smaller than one, while buildings with values of $H / L>1$ tend to be more susceptible to deformations in shear. In the hogging configuration the trend is almost the same, but the shear component starts to be prevalent before the unit value of the aspect ratio. 


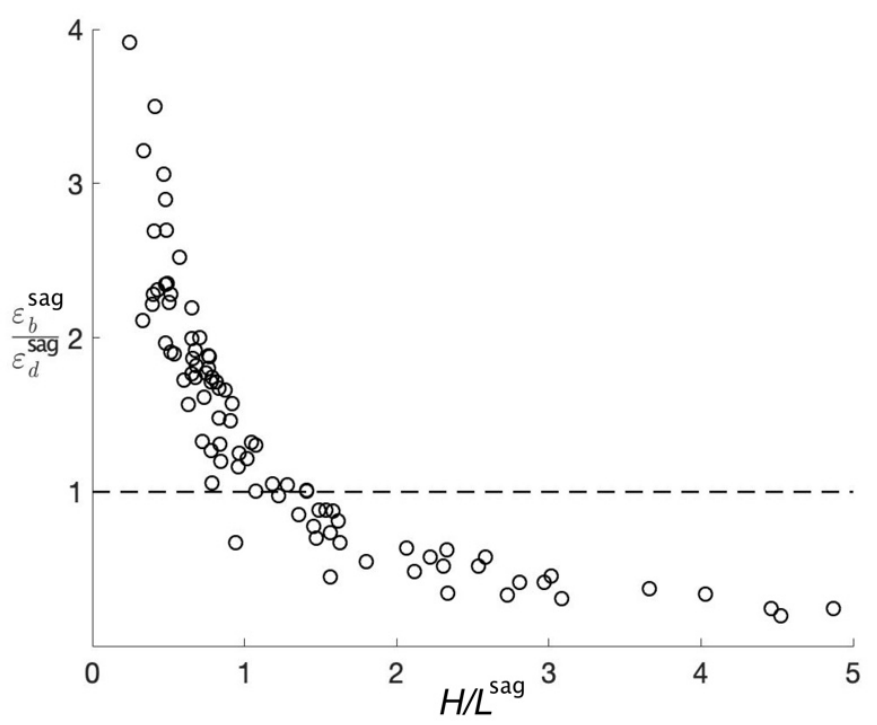

Figure 10: Bending-diagonal strain ratio in sagging vs the aspect ratio.

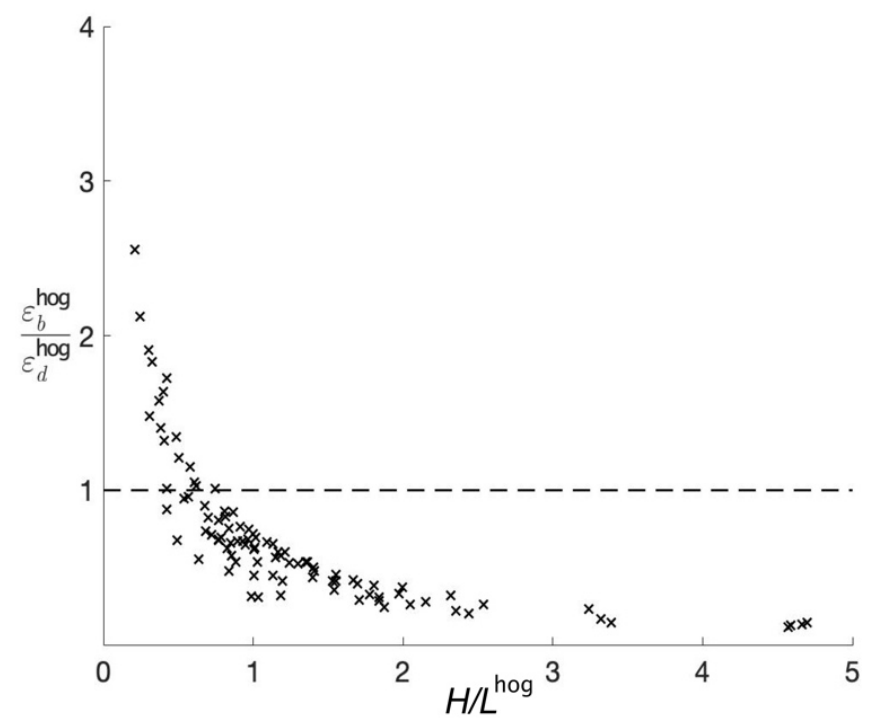

Figure 11: Bending-diagonal strain ratio in hogging vs the aspect ratio.

\section{Conclusion}

This work presents a methodology that exploits MT-InSAR monitoring for assessing the settlement-induced structural damage to buildings near large underground systems. The study has been performed on a test area in central London, along the Crossrail twin tunnels. Cumulative displacements retrieved from a MT-InSAR analysis of the COSMO-SkyMed dataset have been adopted for generating the tunnellinginduced settlement profile of hundreds of buildings, and the corresponding damage assessment. Information related to the construction material, the foundation typology and the age of construction has been used to identify independent blocks of buildings, modelled in the algorithm as equivalent elastic beams. Damage maps have been created to compare the outcomes obtained from the InSAR-measured displacements and the greenfield-based displacements.

The proposed methodology allowed assessment of many structures with a spatial resolution typically not achieved by traditional BRE Sockets. The tool has provided a direct measurement-based estimate of the level of damage on more than 400 structures, confirming that the greenfield prediction is generally conservative. The application of this procedure to post-tunnelling scenarios has the potential to provide a quasireal time identification of vulnerable buildings, with an excellent compromise between accuracy and economic constraints.

The large amount of empirical data available from the SAR Interferometry allows investigation of the actual structural response to settlement for diverse classes of buildings. This opens the possibility of identifying various empirical trends, e.g. related to the construction and foundation typology, that could be used to improve methods of predicting damage for future excavation projects.

\section{References}

Arangio S, Calò F, Di Mauro M, Bonano M, Marsella M and Manunta M (2014). An application of the SBAS-DInSAR technique for the assessment of structural damage in the city of Rome. Structural and Infrastructure Engineering, 10(11):1469-1483.

Boscardin MD and Cording EJ (1989). Building response to excavation-induced settlement. Journal of Geotechnical Engineering, 115(1):1-21.

Burland JB and Wroth CP (1974). Settlement of buildings and associated damage. In SOA Review, Conf. Settlement of structures, Cambridge, pp. 651-654.

Burland JB, Broms BB and De Mello VFB (1977). Behaviour of foundations and structures, state of the art report. In Proceedings of 9th international conference on soil mechanics and foundation engineering. Tokyo. pp. 495-546.

Burland JB, Standing JR, and Jardine PM (2001). Assessing the risk of building damage due to tunnelling-lessons from the Jubilee Line Extension, London. Proceedings of the Fourteenth South-east Asian Geotechnical Conference. Geotechnical Engineering, Hong Kong, vol. 1, pp. 17-44.

Burland JB (2012). Building response to ground movements. In ICE Manual of Geotechnical Engineering Volume I. ICE Publishing, London, UK, pp. 281-295.

Cerchiello V, Tessari G, Velterop E, Riccardi P, Defilippi M and Pasquali P (2017). Building damage risk by modeling interferometric time series. IEEE Geoscience and Remote Sensing Letters, 14(4):509-513. 
Crossrail (2011). Phase 2 Generic Building Damage Assessment Report - Drive X Running Tunnels, Report C122$O V E-C 2-R A N-C R G 01-00015$, London.

Crosetto M, Crippa B, Biescas E, Monserrat O and Agudo M (2005). State of the art of land deformation monitoring using differential SAR interferometry. In ISPRS Hannover Workshop, pp. 17-20.

DeJong MJ, Giardina G, Chalmers B, Lazarus D, Ashworth D, and Mair RJ (2019). The impact of tunnelling on loadbearing masonry buildings on shallow foundations. Proceedings of the ICE - Geotechnical Engineering, accepted for publication.

Di Martire D et al. (2014). Comparison between differential SAR interferometry and ground measurements data in the displacement monitoring of the earth-dam of Conza della Campania (Italy). Remote sensing of environment, 148: 58-69.

DDCMS, Department for Digital, Culture, Media \& Sport (2010). Principles of Selection for Listed Buildings, Government Digital Service, UK.

Ferretti A, Prati C and Rocca F (2000). Nonlinear subsidence rate estimation using permanent scatterers in differential SAR Interferometry. IEEE Transactions on Geoscience and Remote Sensing, 38(5): 2202-2212.

Ferretti A, Prati C and Rocca F (2001). Permanent scatterers in SAR interferometry. IEEE Transactions on Geoscience and Remote Sensing, 39(1):8-20.

Ferretti A et al. (2007). Submillimeter accuracy of InSAR time series: experimental validation. IEEE Transactions on Geoscience and Remote Sensing, 45(5):1142-1153.

Fornaro G, Reale D and Verde S (2013). Bridge thermal dilation monitoring with millimeter sensitivity via multidimensional SAR imaging. IEEE Geoscience and Remote Sensing Letters, 10(4):677-681.

Giardina G, Milillo P, DeJong MJ, Perissin D and Milillo G (2019). Evaluation of monitoring data for post-tunnelling settlement damage assessment. Structural Control and Health Monitoring, 26(2):e2285.

González Martí J, Szabo B and Brzeski J (2015). Use of linked monitoring systems for asset protection at Finsbury Circus during SCL tunnelling for Crossrail Station. In Crossrail Project: Infrastructure design and construction, ICE Publishing, 315-345.

Korff, M and Kaalberg, F (2014). Monitoring dataset of deformations related to deep excavations for North-South line in Amsterdam. In Geotechnical Aspects of Underground Construction in Soft Ground, pp. 321-326.

Milillo P, Riel B, Minchew B, Yun SH, Simons M and Lundgren P (2016). On the synergistic use of SAR constellations' data exploitation for earth science and natural hazard response. IEEE Journal of Selected Topics in Applied Earth Observations and Remote Sensing, 9(3): 1095-1100.

Milillo P, Giardina G, DeJong MJ, Perissin D and Milillo G, (2018). Multi-Temporal In-SAR Structural Damage Assessment: The London Crossrail Case Study. Remote Sensing, 10(2): 287.

Peck, RB (1969). Deep excavations and tunneling in soft ground. Proceedings of the 7th International Conference on Soil Mechanics and Foundation Engineering, pp. 225-290.

Peduto D et al. (2017). Multi-scale analysis of settlementinduced building damage using damage surveys and DInSAR data: A case study in The Netherlands. Engineering Geology, 218: 117-133.

Perissin D, Wang Z and Wang T (2011). The SARPROZ InSAR tool for urban subsidence/manmade structure stability monitoring in China. Proceedings of the ISRSE, Sidney, Australia, pp. 1015.

Pratesi F, Tapete D, Terenzi G, Del Ventisette C and Moretti S (2015). Rating health and stability of engineering structures via classification indexes of InSAR Persistent Scatterers. International Journal of Applied Earth Observation and Geoinformation, 40:81-90.

Salzer JT, Milillo P, Varley N, Perissin D, Pantaleo M and Walter TR (2017). Evaluating links between deformation, topography and surface temperature at volcanic domes: Results from a multi-sensor study at Volcán de Colima, Mexico. Earth and Planetary Science Letters, 479:354-365.

Tapete D and Cigna F (2012). Site-specific analysis of deformation patterns on archaeological heritage by satellite radar interferometry. MRS Online Proceedings Library Archive, 1374:283-295.

Timoshenko, SP (1957). Strength of Materials - Part I, D van Nostrand Co, Inc. London.

Yun SH, Hudnut K, Owen S, Webb F, Simons M, Sacco P, ..., and Milillo P (2015). Rapid damage mapping for the $2015 \mathrm{~m}$ w 7.8 gorkha earthquake using synthetic aperture radar data from cosmo-skymed and alos-2 satellites. Seismological Research Letters, 86(6):1549-1556. 